[Agr. Biol. Chem., Vol. 32, No. 5, p. 624 627, 1968]

\title{
The House Fly Attractants in Mushrooms
}

\author{
Part II. Identification of the Fraction $\mathrm{D}_{3}$ and the Activities \\ of Some Related Compounds
}

\author{
By Toshio Muto, Ryozo Sugawara and Katsuhiko Mizoguchi \\ Laboratory of Pesticide Chemistry, Faculty of Agriculture, Tokyo University \\ of Education, Tokyo, Japan \\ Received November 4, 1967
}

\begin{abstract}
A house fly attracting substance, referred to as $\mathrm{D}_{3}$ in the preceeding paper, ${ }^{1 /}$ was identified with 1,3-diolein.

Among the related compounds, 1 - and 2 -monoolein and $\alpha, \omega$-glycol monooleate with the formula: $\mathrm{CH}_{3}\left(\mathrm{CH}_{2}\right)_{7} \mathrm{CH}=\mathrm{CH}\left(\mathrm{CH}_{2}\right)_{7} \mathrm{COO}\left(\mathrm{CH}_{2}\right)_{n} \mathrm{OH}(n \leqq 6)$, were found to have activities ten times that of 1,3-diolein.
\end{abstract}

From the squeezed juice of the fruiting bodies of a mushroom, Amanita muscaria (L.) Fr., a fraction referred to as $\mathrm{D}_{3}$ was obtained as homogeneous, colorless crystals and characterized as follows: ${ }^{11} \mathrm{mp} 22 \sim 23^{\circ} \mathrm{C}$; an apparent molecular weight determined with Rast's method, 693; Anal. Found: C, 75.51; $\mathrm{H}, 11.54 ; \mathrm{O}, 12.95$ (by difference), Calcd. for a formula, $\mathrm{C}_{39} \mathrm{H}_{72} \mathrm{O}_{5}: \mathrm{C}, 75.43 ; \mathrm{H}, 11.69 ; \mathrm{O}$, $12.88 \%$; M. W. $621 ;[\alpha]_{\mathrm{D}}= \pm 0(1.79 \%$ in chloroform); IR and NMR spectra suggesting the existence of an esterified residue of a long, straight chain, unsaturated fatty acid and a free secondary hydroxyl group, as assigned in Table $\mathrm{I}$.

An intensive search for any hydroxyl esters of unsaturated fatty acids similar to $\mathrm{D}_{3}$ in literatures revealed that the above mentioned properties of $\mathrm{D}_{3}$ well coincide with those of 1,3-diolein. Hence 1,3-diolein was prepared according to the Daubert's established method ${ }^{21}$ comprising acylating 1-monotrityl glycerol with oleoyl chloride and effecting acyl migra-

1) T. Muto and R. Sugawara, Agr. Biol. Chem., 29, 949 (1965).

2) B. F. Daubert and E.S. Lutton, J.A.C.S., 69, 1449 (1947). tion with dry HCl. Trityl alcohol, a byproduct of the above reaction tenaciously contaminating in the end product and having complicated the identification work with the natural product at first, was found to be easily and clearly removed by a silicic acid chromatography, including washing with benzene to remove trityl alcohol and thereafter developing with $2 \% \% \mathrm{v} / \mathrm{v}$ ethyl acetate-benzene to elute 1,3-diolein selectively.

The 1,3-diolein prepared and purified as above and assured to be homogeneous by thinlayer chromatography possessed the following properties: mp $21 \sim 22^{\circ} \mathrm{C}$.; Anal. Found: C, 74.94; $\mathrm{H}, 11.67$. Calcd. for $\mathrm{C}_{39} \mathrm{H}_{72} \mathrm{O}_{5}, \mathrm{C}, 75.43$; $\mathrm{H}, 11.69 \%$ IR and NMR spectra shown in Figs. 1 and 2 were found to be quite identical with those of $\mathrm{D}_{3}$ which were shown along with.

The identity of the fraction $\mathrm{D}_{3}$ with 1,3diolein was further supported by the products of ozonolysis and hydrogenation.

$\mathrm{D}_{3}$ absorbed $2.18 \mathrm{mols}$ of hydrogen when reduced with $50^{\circ} \mathrm{Pd}$-carbon in ethanol. The reduction product was identified with 1,3-distearin, prepared from trityl glycerol and stearoyl chloride on the basis of mixed melting 
Table I. A Qualitative Assignement of the NMR and IR Bands Characterizing the Fraction $\mathrm{D}_{3}$

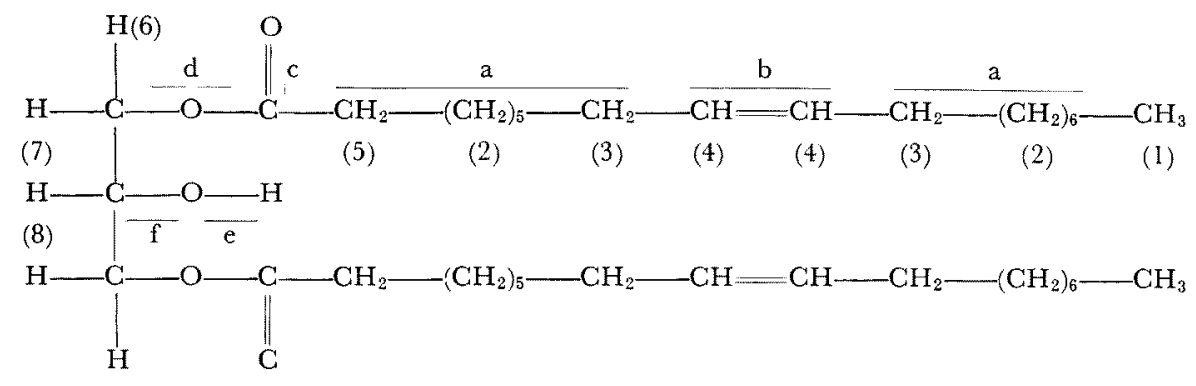
NMR bands* (ppm)
(1) 0.90
(2) 1.28
IR bands $\left(\mathrm{cm}^{-1}\right)$
(3) 1.94
(4) 5.28
(5) 2.30
(6) (7) 4.04 or 4.08
(a) 721
(b) 1655
(c) 1743
(d) 1167
(8) 4.04
(e) 3480
(f) 1091

* Assigned in reference to the spectra catalog of VARIAN associates.

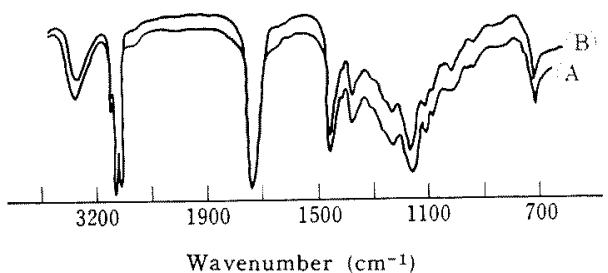

FIG. 1. IR Spectra of the Synthetic 1,3-Diolein (A) and Crystalline $\mathrm{D}_{3}$ (B) in Liquid Film.

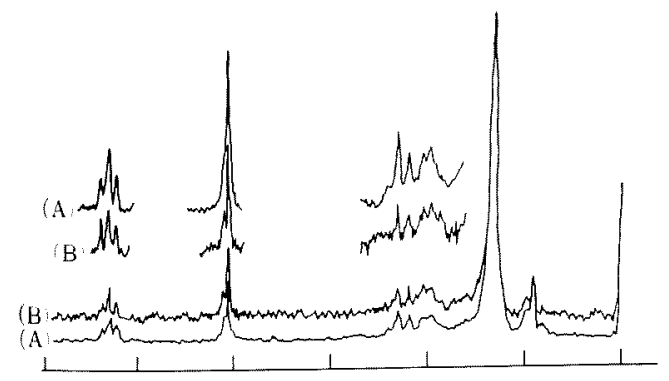

FIG. 2. NMR Spectra of the Synthetic 1,3-Diolein

(A) and Crystalline $\mathrm{D}_{3}(\mathrm{C})$ in $\mathrm{CCl}_{4}$.

$(60 \mathrm{mc}$; tetramethylsilane, internal standard).

point and infrared spectra.

The ozonide obtained by passing ozone through an ice-cooled solutioh of $D_{3}$ in carbon tetrachloride was treated with aqueous ferrous sulfate and steam-distilled into a 2,4-dinitrophenylhydrazine-HCl solution. The hydrazone was identified with that from nonyl aldehyde as had been expected.

Since the identity of $\mathrm{D}_{3}$ with 1,3-diolein was established from the above results and the latter exhibited the same level of house fly attractancy with the former, some related compounds were prepared and their activities compared: 1-monoolein and 2-monoolein were no less than ten times as attractive as 1,3diolein; 3-chloro- and 3-methoxy-1,2-propanediol 1-monooleate and 1,2-propanediol 1monooleate exhibited nearly the same activities with 1,3-diolein; and, glycerol, oleic acid, methyl oleate, triolein, ethylene glycol dioleate and 1,3-distearin had no significant attractancy.

From these results it was primarily considered that at least one esterified residue of an unsaturated, long chain fatty acid together with at least one hydroxyl group, preferably primary one, should be necessary for compounds to exhibit attractancy. On this assumption, as compounds satisfying these 
conditions in one of the simplest combinations, $\alpha,(\omega)$-glycol monooleates with a general formula, $\mathrm{CH}_{3}\left(\mathrm{CH}_{2}\right)_{7} \mathrm{CH}=\mathrm{CH}\left(\mathrm{CH}_{2}\right)_{7} \mathrm{COO}\left(\mathrm{CH}_{2}\right)_{n} \mathrm{OH}(n=$ $2,3,4,5,6,7,8$, and 10 ), were prepared from corresponding glycols and oleoyl chloride.

The activities of the esters with $n$ from 2 through 6 were found at about the same level with 1-monoolein, that is, ten times higher than 1,3-diolein and a significant drop in activities was noted for the esters with $n=8$ and 10. In conclusion, a group of insect attractants represented by the formula: $\mathrm{CH}_{3}\left(\mathrm{CH}_{2}\right)_{7} \mathrm{CH}=\mathrm{CH}\left(\mathrm{CH}_{2}\right)_{7} \mathrm{COO}\left(\mathrm{CH}_{2}\right)_{n} \mathrm{OH}(n \leqq$ 6) has been derived by modifying 1,3-diolein, an identified house fly attractant in Amanita muscaria and proposed as a new type of insect attractant. Results of the modification of the acid portion will be dealed with in another paper.

\section{EXPERIMENTAL}

Preparation of 1,3-diolein. A crude product prepared by the method of Daubert et al.21 was purified by a chromatographic procedure: About $2 \mathrm{~g}$ of the crude product was dissolved in a small amount of benzene and placed on a column of $100 \mathrm{~g}$ silicic acid and trityl alcohol was washed out with about $1000 \mathrm{ml}$ of benzen. Thereafter 1,3-diolein was eluted with $20 \mathrm{v} / \mathrm{v}$ ethyl acetate-benzene: The fractions containing 1,3-diolein appeared after the passage of $300 \mathrm{ml}$ of the solvent and nearly completely eluted after the passage of $1000 \mathrm{ml}$ of the solvent. The solvent was evaporated in vacuo and the residue recrystalized twice from methanol. $m p \quad 21 \sim 22{ }^{\circ}$. Anal. Found: C, 74.94; H, 11.67. Calcd. for $\mathrm{C}_{36} \mathrm{H}_{72} \mathrm{O}_{5}$ : C, 75.43; H, 11.6990 .

Hydrogenation of the $D_{3}$. A solution of $725 \mathrm{mg}$ of $\mathrm{D}_{3}$ in $20 \mathrm{ml}$ of ethanol was hydrogenated under normal pressure and at room temperature with $1 \mathrm{~g}$ of $5 \%$ Pd-Carbon. After one hour absorption of hydrogen was complete $(2.18$ mols $)$. The catalyst was removed by filtration, the solvent evaporated and the residue recrystalized from methanol. $\mathrm{mp}$ $71 \sim 73^{\circ} \mathrm{C}$.

Anal. Found: C, 74.68; H, 12.05. Calcd. for $\mathrm{C}_{39} \mathrm{H}_{76} \mathrm{O}_{5}: \quad \mathrm{C}, 74.94 ; \mathrm{H}, 12.26 \%$.

The product was identified with 1,3-distearen (mp $76 \sim 77^{\circ} \mathrm{C}$ ) prepared from stearolyl chloride and 1 monotrityl glycerol according to the Daubert's method, on the basis of mixed melting point $\left(71 \sim 74^{\circ} \mathrm{C}\right)$ and infrared spectra.

Ozonolysis of $\mathbf{D}_{3}$. Ozone was passed through a solution containing $144 \mathrm{mg}$ of $\mathrm{D}_{3}$ in $10 \mathrm{ml}$ of carbon tetrachloride for about $6 \mathrm{hr}$. The solvent was removed with slight warming and the residue treated with $50 \mathrm{ml}$ of water containing $\mathrm{lg}$ of $\mathrm{FeSO}_{4}$. The precipitate was removed and the filtrate was steamdistilled into a saturated solution of 2,4-dinitrophenylhydrazine in $3.6 \%$ aqueous $\mathrm{HCl}$. The precipitate after having been left to stand overnight was collected by filtration, washed with water and dried in vacuo. The crude product was purified through $a$ silicic acid chromatography using benzene as an eluant and finally recrystalized from ethanol. $\mathrm{mp}$ $98 \sim 99 \mathrm{C}$.

Anal. Found: N. 16.87. Calcd. for $\mathrm{C}_{15} \mathrm{H}_{22} \mathrm{~N}_{4} \mathrm{O}_{4}$ : N, $17.380^{\circ}$. Zmix $359 \mathrm{~m} \mu$ (a, 77.4).

The product was identical with the 2,4-dinitrophenylhydrazone of nonyl aldehyde (bp $82^{\circ} \mathrm{C} . / 4$ mmHg) which had been prepared by treating nonyl bromide with trimethylamine N-oxide according to the method of Volker et al.3) on the basis of mixed melting point, the mp of the synthetic sample $104^{\circ} \mathrm{C}$. and the mixed melting point $101^{\circ} \mathrm{C}$, and $\lambda$ max of synthetic: $359 \mathrm{~m} / \mathrm{a}, 79.6)$, and infrared spectra.

Preparation of the compounds related to 1,3 diolein. 1-Monoolein was prepared from acetoneglycerol according to the method of Daubert et al., ${ }^{4}$ mp 30 33 $\mathrm{C}$ : 2 -monoolein from benzylidene glycerol and oleoyl chloride followed by decomposition with boric acid in triethyl borate according to the method of Martin, ${ }^{5} \mathrm{mp} 28 \sim 30^{\circ} \mathrm{C} ; 1,3$-distearin from l-trityl glycerol and stearoyl chloride, $\mathrm{mp} 76 \sim 77 \mathrm{C} ; 1,2$ propanediol 1 -monooleate from the diol and oleoyl chloride, bp $196 \sim 198^{\circ} \mathrm{C}(2 \mathrm{mmHg})$; glycerol 3-monochlorohydrin l-monooleate from glycerol monochlorohydrin and oleoyl chloride in quinoline, bp $273 \sim 275^{\circ} \mathrm{C}$ (1 $\mathrm{mmHg}$ ); and 3-methoxy glycerol 1 -monooleate by treating 3 -monochlorohydrorin 1 -monooleate with sodium methoxide in methanol, bp $202 \sim 206^{\circ} \mathrm{C}$ (1 $\mathrm{mmHg}$ ).

Preparation of ethylene glycol monooleate. To a solution containing $9 \mathrm{~g}$ of oleoyl chloride and $3 \mathrm{~g}$ of ethylene glycol (about 0.8 molar excess) in $22 \mathrm{ml}$

3) F. Volker and O. Sören, Chem. Ber., 94, 1360 (1961).

4) B. F. Daubert, H. H. Fricke and H. E. Longenecker, J.A.C.S., 65, 2142 (1943).

5) J. B. Martin, ibid., 75, 5482 (1953). 
of dry chloroform was gradually added $6 \mathrm{ml}$ of dry quinoline. The reaction mixture was left to stand at room temperature for $1 \mathrm{hr}$, thereafter refluxed for $4 \mathrm{hr}$. The reaction mixture was cooled, diluted with $50 \mathrm{ml}$ of chloroform and successivelly washed with $2 \mathrm{~N} \mathrm{H}_{2} \mathrm{SO}_{4}$, cold water, 50 aqueous $\mathrm{Na}_{2} \mathrm{CO}_{3}$ and cold water. The solvent was removed, dissolved in a small amount of benzene and placed on a column of $100 \mathrm{~g}$ alumina. After washing with benzene, the monooleate was eluted with about $1000 \mathrm{ml}$ of $5 \%, \mathrm{v} / \mathrm{v}$ methanol-benzene. The solvent was evaporated and the residue distilled. bp $198 \sim 200^{\circ} \mathrm{C}(2 \mathrm{mmHg})$. Yield: $3.7 \mathrm{~g}(340)$. Anal. Found: $\mathrm{C}, 73.54 ; \mathrm{H}$, 11.63. Calcd, for $\mathrm{C}_{20} \mathrm{H}_{38} \mathrm{O}_{3}:$ C, 73.57; $\mathrm{H}, 11.730$.

Preparation of $\alpha, \omega-$ glycol monooleate. According to the just described method, the following monoesters were prepared from the corresponding $\alpha, \omega$-glycols: propylene glycol monooleate, bp 206 $207^{\circ} \mathrm{C}(2 \mathrm{mmHg}$ ), yield $23.5 \%$; tetramethylene glycol monooleate, bp $210 \sim 215^{\circ} \mathrm{C}(2 \mathrm{mmHg})$, yield 16.390 ; pentamethylene glycol monooleate, bp $218 \sim 222^{\circ} \mathrm{C}$ ( $2 \mathrm{mmHg}$ ), yield $28.5 \%$; hexamethylene glycol monooleate, bp $230^{\circ} \mathrm{C}(2 \mathrm{mmHg})$, yield $15.7 \%$; octamethylene glycol monooleate, bp $284 \sim 285^{\circ} \mathrm{C}(3 \mathrm{mmHg})$, yield $14.8, \%$; decamethylene glycol monooleate, $\mathrm{mp}$ $23^{\circ} \mathrm{C}$, yield 25.79 .

House fly attracting activities of 1,3-diolein and related compounds; Typical examples of the house fly attracting tests repeatedly carried out with the above prepared compounds according to the previously reported procedure ${ }^{11}$ will be described below: To petri-dishes, $9 \mathrm{~cm}$ in diameter, containing $50 \mathrm{ml}$ water were respectively added $10 \mathrm{mg}$ and $1 \mathrm{mg}$ of the fraction $D_{3}$ and 1,3-diolein and allowed to stand in the test room with about 1000 flies from a batch having started to hatch before 5 days. The captured flies were 27, 11, 30 and 9 after $16 \mathrm{hr}$. In another similar experiment carried out with $50 \mathrm{mg}$ of glycerol, $10 \mathrm{mg}$ each of triolein, 1,3-diolein, glycerol 3-monochlorohydrin 1-monooleate, 1,3-distearin, 1,2-propanediol 1-monooleate and 3-methoxy glycerol 1monooleate and $1 \mathrm{mg}$ each of 1 -monoolein and 2monoolein, the drowned flies were $1,1,16,15,0$, $17,16,33$, and 19 respectively in the mentioned order. In still another experiment using $1 \mathrm{mg}$ each of 1-monoolein, 1,3-diolein, ethylene glycol monooleate, ethylene glycol dioleate, methyl oleate and
$100 \mathrm{mcg}$ each of ethylene glycol monooleate and 1 monoolein, the captured flies were $24,6,22,1,4,8$ and 12 respectively.

House-fly attracting activities of $\alpha, \omega$-glycol monooleates. To petri-dishes, $9 \mathrm{~cm}$ in diameter, containing $50 \mathrm{ml}$ of water were added $1 \mathrm{mg}$ each of glycol 1-monooleate, 1,3-trimethylene glycol monooleate, 1,4-tetramethylene glycol monooleate, 1,5pentamethylene glycol monooleate, 1,6-hexamethylene glycol monooleate, 1,8-octamethylene glycol monooleate and 1,10-decamethylene glycol monooleate and tested as above. The drowned flies after $16 \mathrm{hr}$ were $31,33,20,28,29,5$ and 2 in the mentioned order.

House-fly attracting activities of ethylene glycol monooleate. (a) At one end of the shelf in the test room, milk and wicked water supply were placed. At a distance of $1.5 \mathrm{~m}$ was placed a petridish, $15 \mathrm{~cm}$ in diameter, filled with $300 \mathrm{ml}$ of water and further $1.5 \mathrm{~m}$ apart was placed $500 \mathrm{mg}$ of the ester dropped to $300 \mathrm{ml}$ of water.

Of about 700 flies having been released in the room, 311 and 31 respectively fell onto the basins of the ester and water, while about 150 tlies still remained swarming over the diet, after 3 days.

(b) Two cylindrical plastic traps, $22 \mathrm{~cm}$ in height and $12 \mathrm{~cm}$ in diameter, provided with a caving-in, inverted funnel-like bottom provided with an opening, $3 \mathrm{~cm}$ in diameter, in the centre were employed. Petri-dishes, $9 \mathrm{~cm}$ in diameter, were attached to the bottom at $t$ distance of about $2 \mathrm{~cm}$ downward with cellophane tape. About $10 \mathrm{ml}$ of the ester was spread in the petri-dish attached to one trap, while the petri-dish attached to another being left empty for comparison. Furthermore, about $100 \mathrm{ml}$ of water containing $1 \mathrm{~g}$ of detergent powder were poured in each of the traps to capture the flics having entered into the traps from the bottom. The containers thus prepared were hanged on the wall of the test room with about 500 fies released, separated about $2 \mathrm{~m}$ and the places were mutually changed every day. After one week, 106 and 26 flies were captured respectively in the test and control traps.

Acknowledgement. This investigation was partly supported by the grant-in-aid of the Ministry of Education. 